\title{
Effect of Preform Thickness and Volume Fraction on Injection Pressure and Mechanical Properties of Resin Transfer Molded Composites
}

\author{
Kristian A. Olivero, Youssef K. Hamidi, \\ Levent AKtas And M. Cengiz Altan* \\ School of Aerospace and Mechanical Engineering \\ University of Oklahoma \\ Norman, Oklahoma, 73019, USA \\ (Received May 2, 2002) \\ (Revised September 15, 2003)
}

\begin{abstract}
An experimental study is performed to characterize the effect of the thickness of random preforms on injection pressure and mechanical properties of resin transfer molded (RTM) parts. Center-gated, disk-shaped parts are molded using two different chopped-strand glass fiber preforms. Both preforms have random microstructure but different planar densities (i.e., different uncompressed layer thicknesses). Tensile strength, short-beam shear strength, and elastic modulus are measured for parts molded with each preform type at three different fiber volume fractions of $6.84,15.55$, and $24.83 \%$. Although mechanical properties are found to increase linearly with volume fraction, significant difference is not observed between disks containing thick and thin mats at equivalent fiber volume fraction.

However at the same fiber content, parts molded with thin mats require significantly lower injection pressures compared to parts containing thick mats. To characterize this phenomenon, a pressure-matching method to determine planar permeability is presented. Permeability values for each preform would provide a quantitative description of the required injection pressure due to changes in preform thickness, with lower permeabilities resulting in higher injection pressure. Transient pressure data is collected at a fixed radial location within the mold cavity during filling for both preforms at three different volume fractions. Permeability is obtained by fitting the theoretical pressure equation derived from Darcy's law to the transient pressure data. Permeability values are found to be as much as $227 \%$ higher for thin mats compared with thick mats at the same fiber content. The results demonstrate that equivalent mechanical properties can be obtained at lower injection pressures by using thinner random mats.
\end{abstract}

KEY WORDS: resin-transfer molding, preform thickness, permeability measurements, mechanical properties.

*Author to whom correspondence should be addressed. E-mail: altan@ou.edu 


\section{INTRODUCTION}

$\mathbf{R}$ ESIN TRANSFER MOLDING (RTM) is a commonly used process to manufacture geometrically complex, medium to large composite parts. The process consists of injecting a polymeric resin under pressure into a mold cavity that contains fibrous preform for reinforcement. The polymeric resin cures in the cavity, typically within several hours, after which the solid part is demolded. Depending on the shape complexity, size, and performance requirements, a wide variety of resins and preform types can be used. RTM has several advantages over other composite forming processes, such as the ability to manufacture high-performance, geometrically complex, medium to large sized parts at low cost and high production rates.

The mechanical performance of resin transfer molded parts is shown to depend on the fiber volume fraction [1,2], microstructure of the preform [3-5], void content [6], and impregnation parameters [7]. In most cases, mechanical properties of composite parts can be improved by increasing fiber volume fraction. Higher fiber volume fractions, however, require increased injection pressure, which may significantly affect the properties of the final part. Patel et al. [8] molded composite parts containing E-glass fibers at constant injection pressure. They observed that doubling the injection pressure results in a $11 \%$ decrease in tensile strength of parts. Similarly, significant variation of the mechanical performance of RTM composites has been observed by Lee and Wei [9] for composites molded at different injection pressures. They reported as much as $38 \%$ decrease in the flexural strength at same fiber volume fraction due to $25 \%$ increase in the injection pressure. Both references suggested that increased injection pressure causes higher flow velocities during molding, leading to more air entrapment at the fluid front and thus increased void formation.

Injection pressure is also influenced by cavity thickness, preform microstructure, and lay up sequence. Brickerton et al. $[10,11]$ reported that even a small variation in mold cavity thickness has a drastic impact on the injection pressure. A decrease in local mold thickness leads to higher local fiber volume fraction, lower preform permeability, and thus, increased molding pressure. Mogavero and Advani [12] investigated the effects of varying the multilayer preform architecture on resin flow. Their results showed that varying lay up order for a fixed number of layers did not result in significant differences in the process. Pearce et al. [13] showed that, using the same fiber type, surface treatment, and fiber volume fraction, permeabilities differ based on fiber weave. Five harness satin weave was found to have the lowest permeability and yielded the parts with the highest interlaminar shear strength (ILSS) compared to five harness satin Injectex and $2 \times 2$ twill weave. $2 \times 2$ twill weave had the highest permeability and lowest ILSS. Adams and Rebenfeld [14] showed that the flow characteristics are very sensitive to preform microstructure. The effect of having multilayer fabric assemblies on the permeability was investigated by using two isotropic fabrics. It was found that the presence of a single high permeability layer among other layers considerably increases the permeability. In addition, the lay up sequence of multilayer fabrics is observed to be important for the average permeability.

In most theoretical models developed for RTM, the required injection pressure is governed by the preform permeability. The commonly used Darcy's law [15] characterizes the permeability as the ratio between the superficial velocity and the pressure drop in the porous media. Several models have been proposed to estimate the value of the permeability for various porous media. Capillary models such as those proposed by 
Carman [16] and Gutowski et al. [17] use the fiber radius and porosity to predict the permeability, but several discrepancies with experimental data have been reported [17-21]. Theoretical models have also been developed for different idealized media structures [18-21]. Most models may not give accurate prediction of permeabilities since fibrous mats used in RTM are often more complex than the idealized unit cell patterns used in theoretical derivations. Thus due to the lack of adequate predictive models, permeability of RTM performs are usually determined experimentally.

A number of permeability measurement methods have been developed; however, there is no standardized measurement technique for RTM applications. Trevino et al. [22] and Young et al. [23] determined unidirectional permeability using two pressure transducers at the inlet and the exit in conjunction with an equation based on Darcy's law applied to their flow geometry. Calhoun et al. [24] presented a technique based on placing several pressure transducers at various locations inside the mold. Adams and Rebenfeld [25-27] developed a technique that quantifies the planar permeability using the position and shape of the advancing resin front as a function of time. A transparent mold was used to enable the monitoring of the advancing front. Other techniques based also on the observation of the moving resin front are common in the literature [10,11,17,25-31]. However, transparent mold walls may not have enough strength to avoid deflection, which has been shown to perturbate the measured permeability values [10,11,22,23]. In addition, the use of a camera or multiple transducers placed on the mold walls may not be practical for many RTM applications.

Lowering injection pressure could considerably decrease the cost of the resin transfer molding process, by allowing less expensive molds and injection equipment to be used. However, lower injection pressure often results in slower fills and longer cycle times. Higher void content and bigger voids are also observed when injection pressure is considerably reduced [32,33]. At significantly slower injection rates, void entrapment in the interstices of the preform tows is observed to increase exponentially with decreasing fluid front velocity. On the other hand, at high injection speeds cited earlier $[8,9,33]$, intertow void entrapment within fiber bundles increases at a slower rate with increasing fluid front velocity. Thus there are tradeoffs associated with the selection of optimum process parameters for a composite part. Although a priori selection of optimum process parameters is desirable, in practice they are most often determined empirically after several production trials.

In the RTM industry, random glass fiber preforms are commonly used because of their availability, lower cost, and planar isotropy. In this study, preform architecture is varied using two different chopped-strand glass fiber mats. Both mat types have identical random microstructure, but have different planar densities and thus different thicknesses. When thinner mats are used to achieve a particular volume fraction, additional layer interfaces are introduced through the thickness. Effects of these additional interfaces on mechanical properties and fill characteristics are not known.

To investigate the potential effects of preform density, six different experimental conditions are studied as described in Table 1. For each experimental condition, five disks are molded using the same process parameters (i.e., 6.84, 15.55 , and $24.83 \%$ fiber volume fractions for both thick and thin preform types). Table 1 contains the designation symbol, preform type, number of layers, and the corresponding fiber volume fraction for each case studied along with the corresponding confidence intervals determined at $95 \%$. For each of the six cases given in Table 1, test samples are cut from disk-shaped composite parts, and then tensile strength, short-beam shear strength, and elastic modulus are measured. 
Table 1. Experimental configurations used to examine effect of preform thickness and fiber volume fraction. Five composite disks are molded using identical process parameters for each configuration.

\begin{tabular}{|c|c|c|}
\hline Designation & Description & Volume Fraction $\left(v_{f}\right)$ \\
\hline TN4 & $\begin{array}{l}4 \text { thin layers of chapped-strand glass fiber mat. } \\
\text { Listed planar density: } 0.2280 \mathrm{~kg} / \mathrm{m}^{2} \\
\text { Measured planar density: } 0.2098 \mathrm{~kg} / \mathrm{m}^{2} \pm 0.0151 \mathrm{~kg} / \mathrm{m}^{2}\end{array}$ & $6.84 \% \pm 0.93 \%$ \\
\hline TN8 & $\begin{array}{l}8 \text { thin layers of chapped-strand glass fiber mat. } \\
\text { Listed planar density: } 0.2280 \mathrm{~kg} / \mathrm{m}^{2} \\
\text { Measured planar density: } 0.2126 \mathrm{~kg} / \mathrm{m}^{2} \pm 0.0071 \mathrm{~kg} / \mathrm{m}^{2}\end{array}$ & $15.55 \% \pm 2.10 \%$ \\
\hline TN12 & $\begin{array}{l}12 \text { thin layers of chapped-strand glass fiber mat. } \\
\text { Listed planar density: } 0.2280 \mathrm{~kg} / \mathrm{m}^{2} \\
\text { Measured planar density: } 0.2152 \mathrm{~kg} / \mathrm{m}^{2} \pm 0.0063 \mathrm{~kg} / \mathrm{m}^{2}\end{array}$ & $24.83 \% \pm 1.47 \%$ \\
\hline TK2 & $\begin{array}{l}2 \text { thick layers of chapped-strand glass fiber mat. } \\
\text { Listed planar density: } 0.4590 \mathrm{~kg} / \mathrm{m}^{2} \\
\text { Measured planar density: } 0.4432 \mathrm{~kg} / \mathrm{m}^{2} \pm 0.0287 \mathrm{~kg} / \mathrm{m}^{2}\end{array}$ & $6.84 \% \pm 0.69 \%$ \\
\hline TK4 & $\begin{array}{l}4 \text { thick layers of chapped-strand glass fiber mat. } \\
\text { Listed planar density: } 0.4590 \mathrm{~kg} / \mathrm{m}^{2} \\
\text { Measured planar density: } 0.4371 \mathrm{~kg} / \mathrm{m}^{2} \pm 0.0182 \mathrm{~kg} / \mathrm{m}^{2}\end{array}$ & $15.55 \% \pm 0.27 \%$ \\
\hline TK6 & $\begin{array}{l}6 \text { thick layers of chapped-strand glass fiber mat. } \\
\text { Listed planar density: } 0.4590 \mathrm{~kg} / \mathrm{m}^{2} \\
\text { Measured planar density: } 0.4353 \mathrm{~kg} / \mathrm{m}^{2} \pm 0.0147 \mathrm{~kg} / \mathrm{m}^{2}\end{array}$ & $24.83 \% \pm 1.44 \%$ \\
\hline
\end{tabular}

Transient pressure data was recorded at a radial location $12.7 \mathrm{~mm}$ away from the disk center during molding. A pressure-matching technique is presented in this work, in which the planar permeability is determined by fitting a theoretical pressure expression derived from Darcy's law to the measured transient pressure data. Permeabilities of different configuration are compared in order to quantify the effect of preform density on injection pressure.

\section{EXPERIMENTAL SETUP}

\section{Molding Apparatus Used to Fabricate RTM Parts}

An experimental molding setup is constructed to fabricate resin transfer molded disks. The setup, depicted in Figure 1, is composed of a molding press assembly that injects a two-part thermosetting resin at constant flow rate into a modular disk-shaped mold cavity. The molding press assembly contains two hollow cylinders, which hold resin and curing agent respectively. Plungers attached to the top plate of the press displace the resin and curing agent in the cylinders by equal distances when the top plate is pushed down. The flow from the two cylinders merges, and then passes through a Statomix brand motionless inline mixer (Technical Resin Packaging, Inc.), which facilitates thorough mixing of the two components. The outer body of the mixer is a $155 \mathrm{~mm}$ long, polypropylene tube (ID $=5 \mathrm{~mm}, \mathrm{OD}=8 \mathrm{~mm}$ ). Inside the tube, mixing is performed by 32 alternating helical segments, visible in Figure 2. The mixture is then injected into the center of the disk-shaped cavity. The entire setup is mounted on a hydraulic press frame (ARCAN, 80,000 lb capacity), which provides the force necessary to inject the polymer 


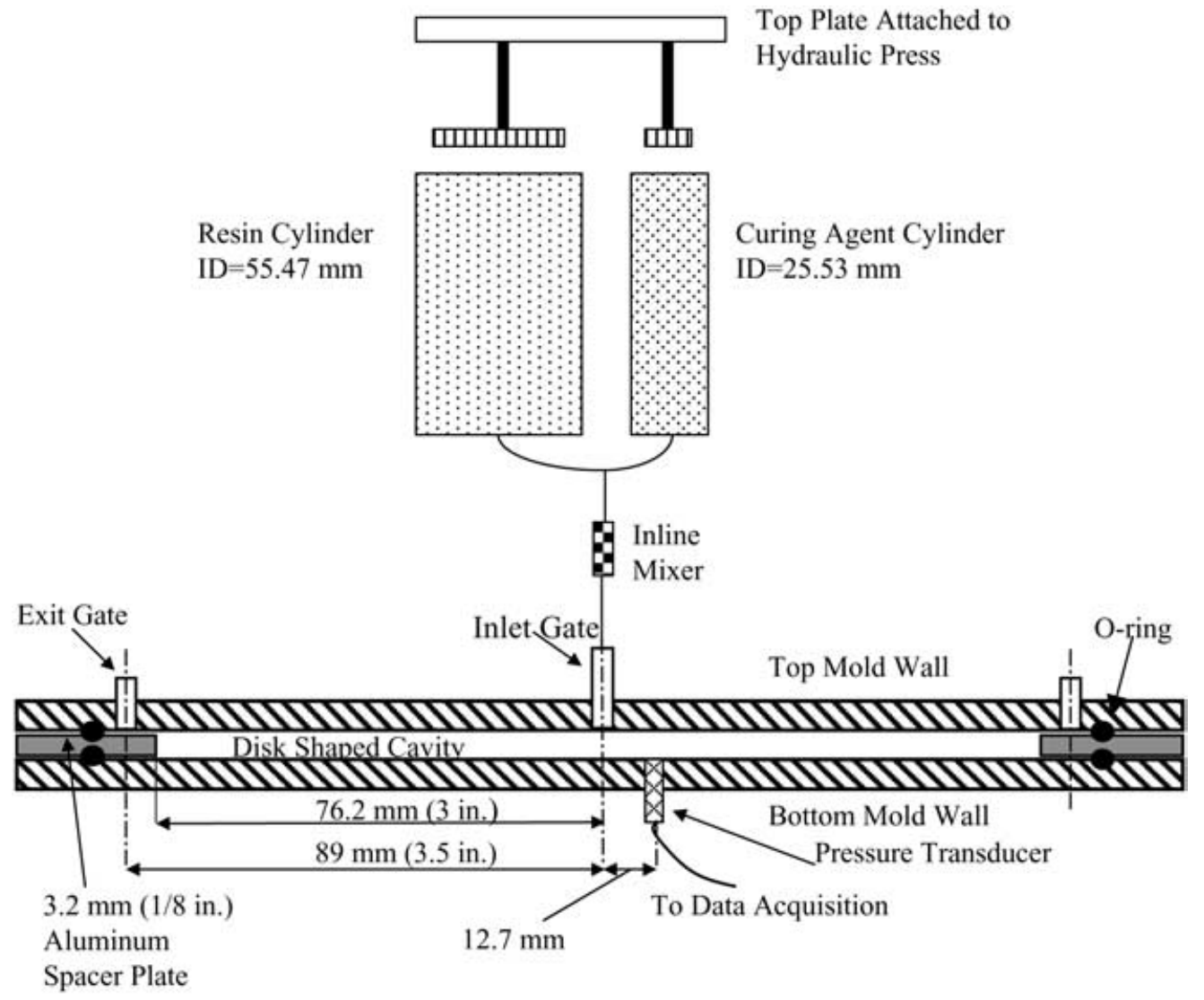

Figure 1. Setup used to fabricate RTM parts and measure pressure to determine permeability.

mixture. The press moves at a constant linear velocity of $2 \times 10^{-3} \mathrm{~m} / \mathrm{s}$ through most of its $152.4 \mathrm{~mm}$ (6 in.) stroke, thus resulting in constant injection rate.

The mold cavity, shown in Figure 1, is constructed by placing a $3.18 \mathrm{~mm}(0.125 \mathrm{in}$.) thick aluminum spacer plate between two $6.35-\mathrm{mm}$ ( $0.25 \mathrm{in}$.) thick aluminum mold walls. A $152.4 \mathrm{~mm}$ (6.0 in.) diameter circle is cut from the center of the spacer plate to form the disk-shaped cavity. Parts with different thickness can be molded by changing the spacer plate. In the current study, however, only $3.18-\mathrm{mm}(0.125 \mathrm{in}$.) thick spacer plates are used. Holding a packing pressure on the mold after filling has been demonstrated to produce higher quality parts [34]. Thus in order to maintain pressure in the cavity, a 4-mm wide o-ring groove is machined into each mold wall to form a pressure tight seal. Depending on the compression of the o-ring, molded disks are usually slightly thicker than $3.18 \mathrm{~mm}$. An inlet gate, positioned at the center of the mold cavity, is drilled and tapped for a polypropylene hose fitting $(\mathrm{ID}=6.2 \mathrm{~mm}$ ) on the top mold wall. Four vents are also drilled in the top mold wall and tapped for hose fittings $(\mathrm{ID}=1.6 \mathrm{~mm})$. Vents are positioned evenly around the cavity at a radius of $88.9 \mathrm{~mm}$ ( $3.5 \mathrm{in}$.). After the mold is completely full, the press is run for a few additional seconds until resin comes out of all four vent hoses. Then four vent hoses and the inlet hose are sequentially clamped to maintain the final fill pressure. 


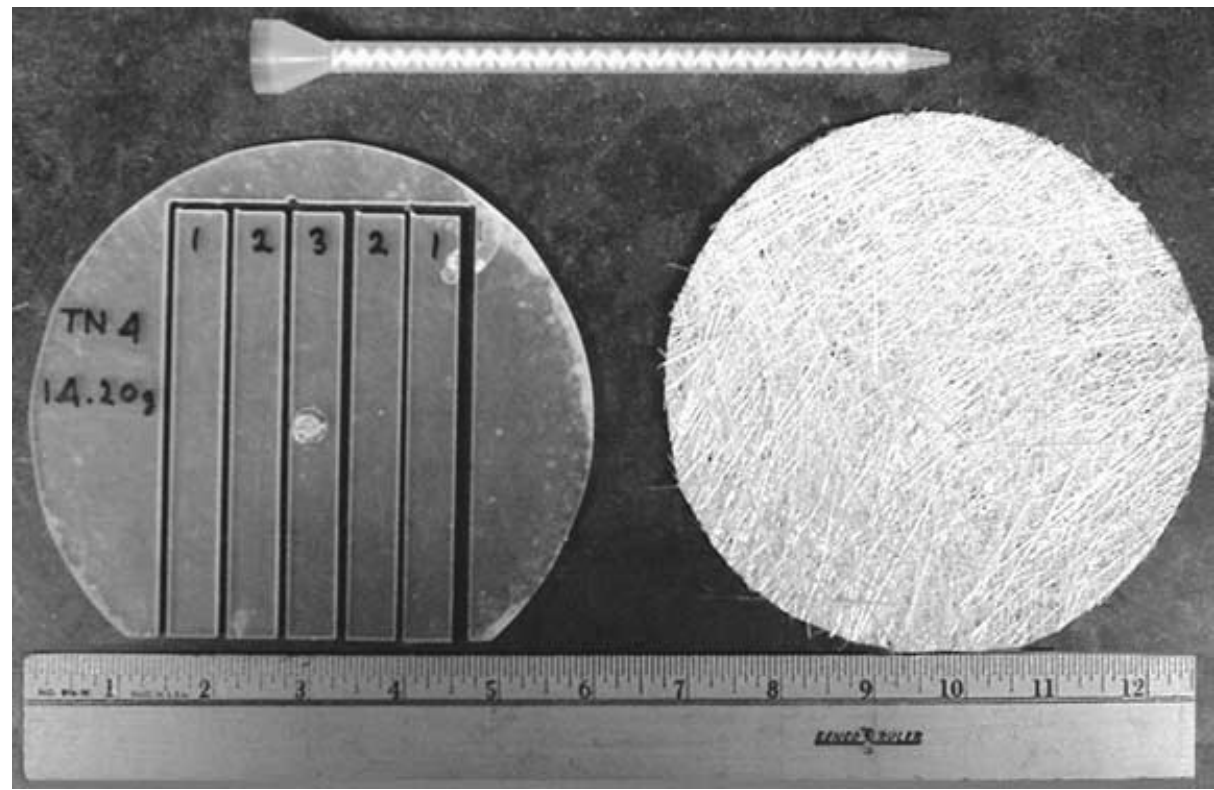

Figure 2. Photograph of a molded disk cut into five tensile test specimens (left), chopped-strand glass fiber mat (right), and Statomix ${ }^{\circledR}$ inline mixer (top).

Two different chopped-strand glass fiber mats having different planar densities i.e., $0.2280 \mathrm{~kg} / \mathrm{m}^{2}\left(0.75 \mathrm{oz} / \mathrm{ft}^{2}\right.$, Fiberglast part \#248), and $0.4590 \mathrm{~kg} / \mathrm{m}^{2}\left(1.5 \mathrm{oz} / \mathrm{ft}^{2}\right.$, Fiberglast part \#250) are used in this study. Preforms are cut into $152.4 \mathrm{~mm}$ (6.0 in.) diameter circles and stacked in the mold cavity to achieve desired fiber volume fraction prior to filling. One of the dense mats cut into a 152.4-mm circle is visible on the right in Figure 2. Mats have a randomly distributed, in-plane fiber orientation. For this study, three fiber volume fractions are investigated (i.e., 6.84, 15.55, and 24.83\%). These volume fractions are achieved by stacking 2, 4, or 6 layers of the thick mats, or 4, 8, or 12 layers of the thin mats respectively. Details for each of the six resulting fiber configurations are listed in Table 1.

In order to characterize planar density variation of the fibrous mats, more than five hundred circular performs $(D=152.4 \mathrm{~mm})$ from both thin and thick mats are cut and weighed. The planar density of the thick mats is measured to be $0.4356 \mathrm{~kg} / \mathrm{m}^{2}$, with a standard deviation of $0.0449 \mathrm{~kg} / \mathrm{m}^{2}$, which is slightly lower than the $0.4590 \mathrm{~kg} / \mathrm{m}^{2}$ reported by the manufacturer. Planar densities of the individual mats are observed in the range of $0.3141-0.5564 \mathrm{~kg} / \mathrm{m}^{2}$, representing a $77.14 \%$ variation. Average planar density for thin mats is measured to be $0.2148 \mathrm{~kg} / \mathrm{m}^{2}$ with a standard deviation of $0.0262 \mathrm{~kg} / \mathrm{m}^{2}$, which is also lower than the reported value of $0.2280 \mathrm{~kg} / \mathrm{m}^{2}$. Thin mats exhibit a greater variation of $107.34 \%$, with individual values ranging between 0.1420 and $0.2944 \mathrm{~kg} / \mathrm{m}^{2}$. To minimize the effect of preform density variation and achieve the same fiber content in each disk group, layers of prefroms are judiciously selected for each molded disk.

To determine the exact fiber volume fraction utilized in this study, density of E-glass fibers is measured by using a $100 \mathrm{~mL}$ GARDCO ${ }^{\circledR}$ standard specific gravity cup. In a series of five experiments, E-glass fiber samples of different weights are first weighed dry in air, and then weighed again while submerged in a degassed vegetable oil inside the specific gravity cup. Commonly used liquids such as water and ethanol are not utilized since the 
E-glass fibers, when submerged in such liquids, are not completely wetted. Hence, the air trapped within fiber tows results in a reduced wet weight and yields erroneously low values for fiber density. However, a thorough degassing technique used with vegetable oil allowed a consistent measurement of E-glass density, irrespective of the amount of fibers used. The five experiments conducted for E-glass samples with masses ranging between 4 and $12 \mathrm{~g}$, indicated an average density of $2553 \mathrm{~kg} / \mathrm{m}^{3}$ with a standard deviation of $39 \mathrm{~kg} / \mathrm{m}^{3}$.

An epoxy resin, EPON 815C, manufactured by Shell Chemicals, is selected for the molding experiments. Attractive properties of this resin include its low viscosity, which facilitates moderate injection pressures, and its low toxicity. The desired gel time of about $20 \mathrm{~min}$ is achieved by selecting EPICURE 3282 (Shell Chemicals) as the curing agent. The internal diameters of the two stainless steel cylinders are machined to 55.47 and $25.53 \mathrm{~mm}$ in order to achieve the appropriate mix ratio, 4.7 to 1 by volume, of resin to curing agent. The polymer mixture has approximately 960 centipoise viscosity before cross-linking begins. Cylinders contain enough resin and curing agent to mold six of the disks during a single stroke. Thus, six disks are fabricated during each molding session utilizing six identical molds.

The parts are molded at constant flow rate, with fill times ranging between 6 and $9 \mathrm{~s}$, depending on fiber volume fraction. Fill times are consistent with those expected in industrial molding of similarly sized parts. After the vents and inlet hose are clamped to maintain the pressure, the part is left to cure in the mold for $48 \mathrm{~h}$ before demolding. To ensure the completion of cross-linking and full development of mechanical properties, the disks are post cured at room temperature for a minimum of two additional weeks before they are machined, polished, and tested.

\section{Tensile Testing of Molded Composites}

Each molded disk is cut into five $114.3 \times 12.7 \times 3.18 \mathrm{~mm}(4.50 \times 0.50 \times 0.125 \mathrm{in}$. $)$ rectangular tensile test specimens in accordance with ASTM D3039/D3039M standard [35]. Figure 2 depicts the relative spatial positions of the five specimens within the molded disk. Angular orientation of the specimen array within each disk is arbitrary due to random planar fiber orientation. Each disk yields a center specimen that contains the inlet gate at its center (marked as 3 in Figure 2). Two specimens at position 2 are located symmetrically on either side of the center specimen, and two specimens at position 1 are near the edge of the disk as shown in Figure 2. A cutting template is used to hold the disk in place on a vertical milling machine so specimens can be cut to the best tolerances possible. Each cut specimen is slightly polished with sandpaper to remove edge defects that might result in premature mechanical failure. A micrometer is used to measure thickness and width at five locations on each specimen. Variations in the injection pressure and difference in the o-ring compression during molding result in a thickness variation up to $0.6 \mathrm{~mm}$ among specimens. Average measured thickness of all specimens is $4.34 \mathrm{~mm}$, with a standard deviation of $0.46 \mathrm{~mm}$. The measured variations in molded disk thicknesses, combined with the slight variations in fiber masses used for different disks are utilized to calculate each disk's individual fiber volume fraction. Using the E-glass density of $2553 \mathrm{~kg} / \mathrm{m}^{3}$ measured earlier, the amount of preform used, and the total disk volume, individual fiber volume fraction for each molded disk is calculated. Average fiber volume fractions for each configuration, along with confidence intervals determined at $95 \%$ are presented in Table 1. 


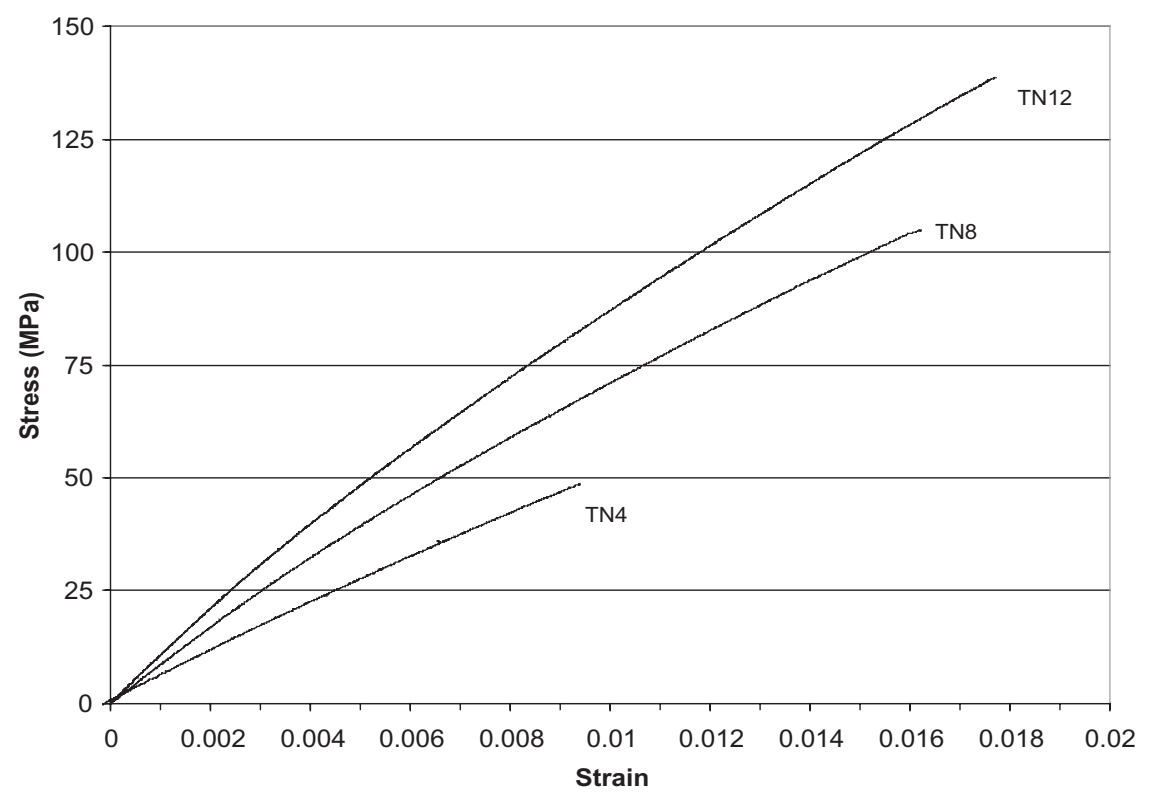

Figure 3. Representative stress-strain curves from tensile tested specimens. TN4: 4 layers of thin mats (i.e., $v_{f}=6.84 \%$ ); TN8: 8 layers of thin mats (i.e., $v_{f}=15.55 \%$ ); TN12: 12 layers of thin mats (i.e., $v_{f}=24.83 \%$ ).

As shown in Figure 2, the sample from position 3 contains a surface defect at its center as the cured resin at the inlet has been broken off during demolding. These specimens are not tested, as they are prone to premature failure. Half of the specimens from position 1 , and all of the specimens from position 2 are tested under tension using the MTS machine at room temperature, thus yielding fifteen tensile samples for each of the six experimental conditions. The force is increased linearly from 0 to $8.90 \mathrm{kN}(0-2000 \mathrm{lb})$ over $120 \mathrm{~s}$; depending on fiber content specimens typically fail at forces between 2.7 and $8.0 \mathrm{kN}$ $(600-1800 \mathrm{lb})$. Strain is measured directly using an extensometer attached over a $25.4 \mathrm{~mm}$ (1.00 in.) span at the center of the specimen during testing. The stress is calculated by dividing the force by the cross sectional area, and stress-strain curves are generated for each specimen. Three representative stress-strain curves for specimens from position 1 molded at three fiber contents are depicted in Figure 3. Stress-strain curves have no distinct yield point, and exhibit nearly linear behavior until failure. From the tensile test data, maximum stress is recorded for each specimen as the ultimate tensile strength (UTS), and elastic modulus is calculated over the linear region between 1000 and 3000 microstrain, as specified by ASTM D3039/D3039M. For each configuration, the ultimate tensile strength and elastic modulus are taken as the average of the fifteen values obtained from the tested specimens.

\section{Three-point Bending Test of Molded Composites}

Additional mechanical characterization of the parts is carried out by a three-point bending test to determine the short-beam shear strength. Short-beam shear strength can be a good indicator of fiber-matrix adhesion and interlaminar shear strength. Testing is 
performed in accordance with ASTM D2344/D2344M standard for short-beam strength of high-modulus fiber-reinforced composite materials [36]. Unused specimens from position 1 in each one of the five disks are utilized for three-point bending test. Threepoint bending specimens are prepared by cutting the sample from position 1 into three $38.1 \mathrm{~mm}$-long (1.5 in.) segments. An adjustable three-point bend fixture (MTS Series \#642) mounted on the MTS machine is used to test the center segment, which is symmetric with respect to the radial axis. The specimen is placed on two $3.175 \mathrm{~mm}(0.125 \mathrm{in}$.) diameter bottom rollers, adjusted to a center-to-center span of $25.4 \mathrm{~mm}$ (1 in.). A third roller, $6.35 \mathrm{~mm}(0.25 \mathrm{in}$.) in diameter, exerts force on the specimen center from above, moving down at a constant linear displacement of $1.27 \mathrm{~mm} / \mathrm{min}$. (0.05 in. $/ \mathrm{min}$.). After failure, specimens are examined visually to ensure the failure mechanism is by shear, which is indicated by a white failure band through the thickness for these particular specimens. For each experimental configuration, the short-beam shear strength is taken as the average of the five values obtained from each three-point bending specimen.

\section{Pressure Measurement During Mold Filling}

During filling, transient pressure data is collected at a radial location of $12.7 \mathrm{~mm}$ (0.5 in.) away from the inlet. Pressure is measured using a pressure transducer (Omega Model PX180-100GV, 100 psi max, 0.3\% accuracy) flush mounted on the bottom mold wall, as depicted in Figure 1. The pressure transducer is attached to a custom-built signal amplification circuit based on an AD620 in-amp, which conditions the signal for the data acquisition system by amplifying voltage, isolating the signal, and lowering transducer output impedance. Voltage amplification is adjustable by changing resistors in the circuit with typical amplifications being on the order of 100. Pressure data is sampled at $10 \mathrm{hz}$ using a laptop computer controlled Omega Daqbook data acquisition system.

For pressure measurements, mold filling experiments are performed using corn syrup as the filling fluid to avoid damaging the pressure transducer. Corn syrup is diluted with water to adjust its viscosity, allowing fill pressures for all the six mat configurations to be obtained within the pressure transducer's most accurate range. Viscosities ranging from 39 centipoise for high fiber volume fraction experiments to 1464 centipoise for low fiber volume fraction experiments yield moderate pressure levels and enable repeatable, noise free data collection. A modified mold cavity is utilized to obtain accurate pressure measurements. Transient pressure increase is very sensitive to gap width, thus the o-ring, which may cause a small but uncontrolled increase in cavity thickness, is not used. Additionally, mold release is not necessary, and mold surfaces are polished as the motion of fluid front may be adversely affected by slight anomalies on the mold walls.

Representative pressure measurements at $12.7 \mathrm{~mm}$ away from the inlet during filling experiments are shown in Figure 4. Pressure data for each fiber content are included where TK2, TK4, and TK6 designate thick mats, and TN4, TN8, and TN12 designate thin mats. Although filling starts at $t=0 \mathrm{~s}$, finite pressure values are not recorded until fluid front contacts the transducer several seconds later. The fillings are carried out at constant flow rate, and thus, fluid front contacts the transducer earlier in molds with higher fiber content. Start times for the data presented in Figure 4 have been shifted a few seconds to allow each pressure curve to be clearly observed, as this time shift is inconsequential in the way the data is used. In these experiments, the flow continues several seconds after the 


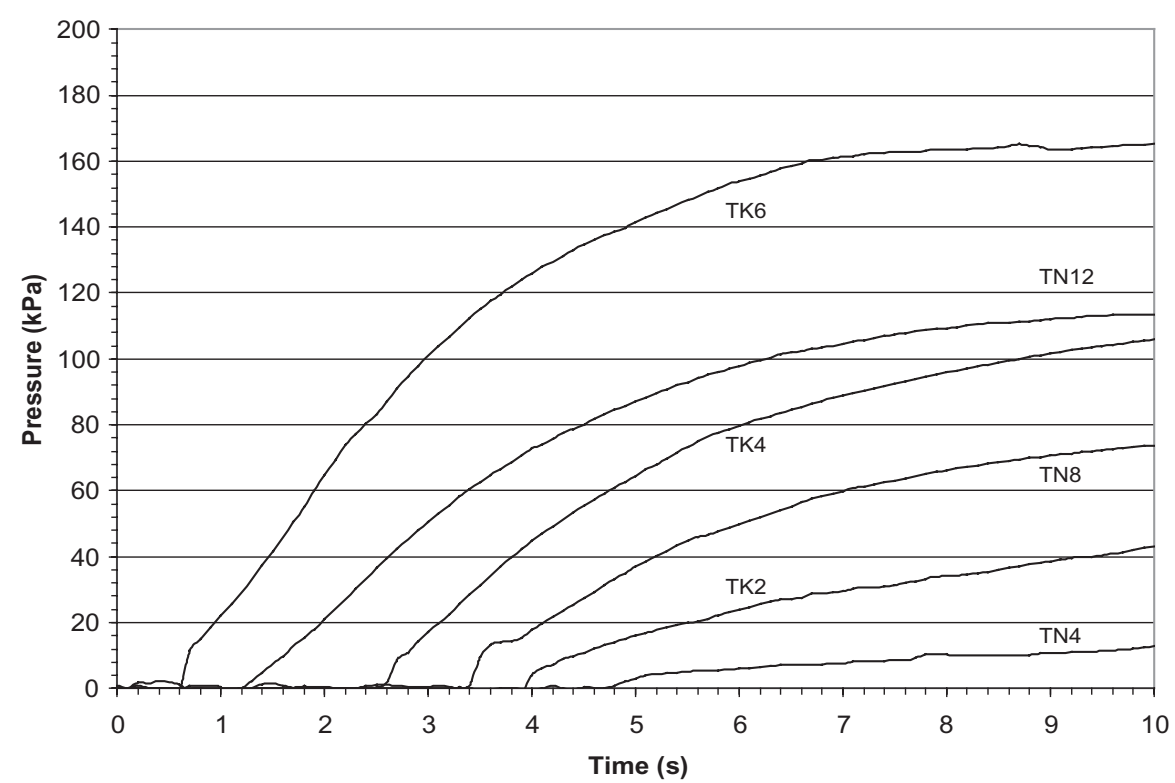

Figure 4. Example pressure curves from filling disks containing each of the six preform configurations.

mold cavity is completely full as the exit hoses are left unclamped to allow steady discharge of the fluid.

\section{PRESSURE IN A DISK-SHAPED CAVITY CONTAINING POROUS MEDIA}

Darcy's law [15] is used to model flow through a porous media by relating velocity to pressure gradient with a permeability tensor,

$$
\mathbf{u}=-\frac{1}{\mu} \mathbf{K} \nabla p
$$

In Equation (1), $\mathbf{u}$ is the average Darcy velocity, $\mu$ is the dynamic viscosity, $\nabla p$ is the pressure gradient, and $\mathbf{K}$ is the second-order permeability tensor. For the molding of center-gated, disk-shaped parts, purely radial flow in the cavity is expected. There is no velocity component or non-zero derivatives in the tangential direction, thus the flow is axisymmetric. Figure 5 depicts the cross section of a center-gated disk labeled with the coordinate system used. Important dimensions in Figure 5 are the half gap width, $H$, and the transient radial location of the fluid front, $R_{f}(t)$. In radial coordinates and with axisymmetric radial flow assumption, Darcy's law simplifies to the following,

$$
u_{r}=-\frac{1}{\mu} \frac{\partial p}{\partial r} K_{r r}
$$




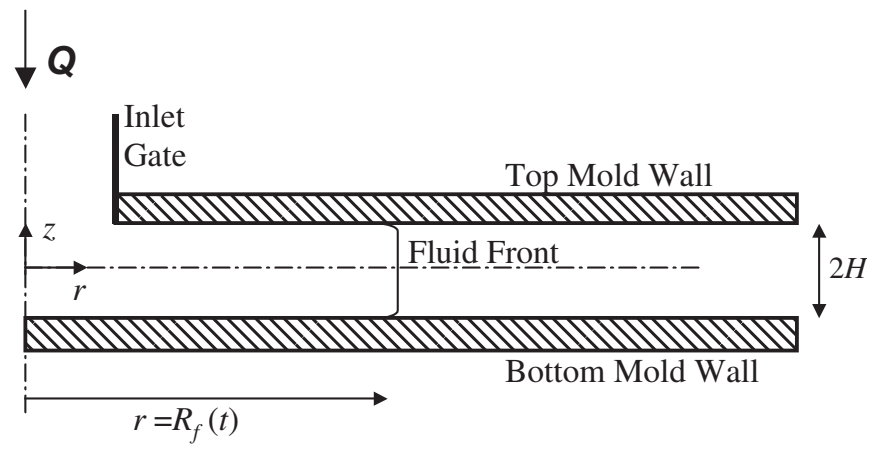

Figure 5. Cross section of disk shaped cavity labeled for pressure calculations. $R_{f}$ is the transient radial location of the fluid front during filling.

where $u_{r}$ is the radial velocity component, and $K_{r r}$ is the radial permeability. In addition, conservation of mass simplifies to,

$$
\frac{\partial}{\partial r}\left(r u_{r}\right)=0
$$

Equation (3) can be integrated easily to yield,

$$
r u_{r}=c(t)
$$

where $c(t)$ is only dependent on time. Equation (4) is substituted into Equation (2) to obtain,

$$
\frac{d r}{r}=-\frac{K_{r r}}{\mu} \frac{d p}{c(t)}
$$

Equation (5) is integrated from the radius of the pressure transducer, $r=R$, to the radial location of the fluid front, $r=R_{f}(t)$, and from the pressures at the transducer, $p=P(t)$, to the pressure at the free surface, $P_{f}$, to obtain,

$$
-\frac{K_{r r}}{c(t) \mu}\left(P_{f}-P(t)\right)=\ln \left(\frac{R_{f}(t)}{R}\right)
$$

The velocity in Equation (4) can be expressed in terms of the volume flow rate, $Q$, and geometry using the volume flowing through the area of a ring in the disk at the radius of the transducer, $R$, as,

$$
u_{r}=\frac{c(t)}{R}=\frac{Q}{A}=\frac{Q}{\left(1-v_{f}\right) 4 \pi R H}
$$

where $v_{f}$ is the perform volume fraction. The velocity $u_{r}$ remains constant at a given radial location if the fluid is injected at constant volume flow rate; thus, $c$ is a constant that does not depend on time. At the free surface, the fluid front is in contact with atmosphere if the 
vents are kept open during filling. Thus, $P_{f}=0$, and Equations (6) and (7) can be combined to yield,

$$
P(t)=\frac{Q \mu}{\left(1-v_{f}\right) 4 \pi H K_{r r}} \ln \frac{R_{f}(t)}{R} .
$$

Equation (8) gives the transient pressure in a disk at the radius $R$ based on the flow rate, viscosity, gap width, radial permeability, and the radial position of the fluid air interface, $R_{f}(t)$.

\section{Permeability Measurement using a Single Pressure Transducer}

The majority of methods for permeability measurement published in literature require the use of at least two pressure transducers placed at different locations in the mold cavity $[29,37,38]$. These transducers are used to measure a pressure difference between two locations, from which the permeability is directly calculated from Darcy's equation. Equation (8), however, is in a form that allows the permeability to be calculated using the known pressure at the fluid front and data from only one pressure transducer [39]. The viscosity, gap width, flow rate, and volume fraction are measured prior to filling. The location of the fluid front with time, $R_{f}(t)$, is obtained based on the volume flow rate and geometry. The volume of the disk, $V$, that has been filled at a time, $t$, is given by the following two expressions.

$$
\begin{gathered}
V=Q t \\
V=2\left(1-v_{f}\right) \pi H R_{f}^{2}(t) .
\end{gathered}
$$

These are combined to obtain $R_{f}(t)$ in terms of experimental parameters and time,

$$
R_{f}(t)=\sqrt{\frac{Q t}{2\left(1-v_{f}\right) \pi H}} .
$$

Equation (11) is substituted into Equation (8), to obtain the final form used to obtain permeability from a single set of pressure data,

$$
P(t)=\frac{Q \mu}{\left(1-v_{f}\right) 4 \pi H K_{r r}} \ln \frac{\sqrt{Q t / 2\left(1-v_{f}\right) \pi H}}{R} .
$$

The permeability, $K_{r r}$, can now be obtained by using a least squares curve fit varying $K_{r r}$ to match Equation (12) to transient pressure data. The concept of obtaining permeability by this pressure-matching technique is similar to the one presented by Bickerton et al. [11] where planar anisotropic permeabilities of stitched fabrics are determined by observing the shape of fluid front and subsequently matching the numerically obtained and experimentally measured pressure histories. 


\section{RESULTS AND DISCUSSION}

\section{Mechanical Testing Results}

Five disks are molded to characterize mechanical properties for each of the six preform configurations designated in Table 1. All specimens from position 2 and half of the specimens from position 1 are utilized to characterize the ultimate tensile strength of each preform configuration. Thus fifteen specimens are tested under tension as described by ASTM D3039/D3039M. In a previous study of composite disks molded similarly, tensile results were found to be statistically indistinguishable for samples from positions 1 and 2 [40]. Thus, data from these specimens are combined to reduce statistical variation, yielding 15 specimens for each data point. The use of a large number of specimens is preferred because random preforms have been shown to have large local variations in planar density [28], which leads to higher statistical variation in mechanical testing results. Thus, a total of ninety specimens are tested under tensile loading.

Measured values for ultimate tensile strength for each configuration are presented in Figure 6. Strength values are plotted with error bars calculated using a 95\% confidence interval. Tensile strength is observed to be equivalent for thick and thin mats within the range of statistical error at each of the three equivalent fiber volume fractions, with thick mats exhibiting slightly higher strengths at the lower two fiber volume fractions, and thin mats having slightly higher strength at highest fiber content. Both thick and thin mat strengths are observed to increase linearly by increasing fiber content, with $130 \%$ increase in strength for thick mats when fiber content is increased from 6.84 to $24.83 \%$. Thin mats exhibit a $169 \%$ increase in strength over the same range of fiber content. For these six cases the uncertainty using the $95 \%$ confidence interval ranges from 7.5 to $18.2 \%$ with an average value of $13.4 \%$.

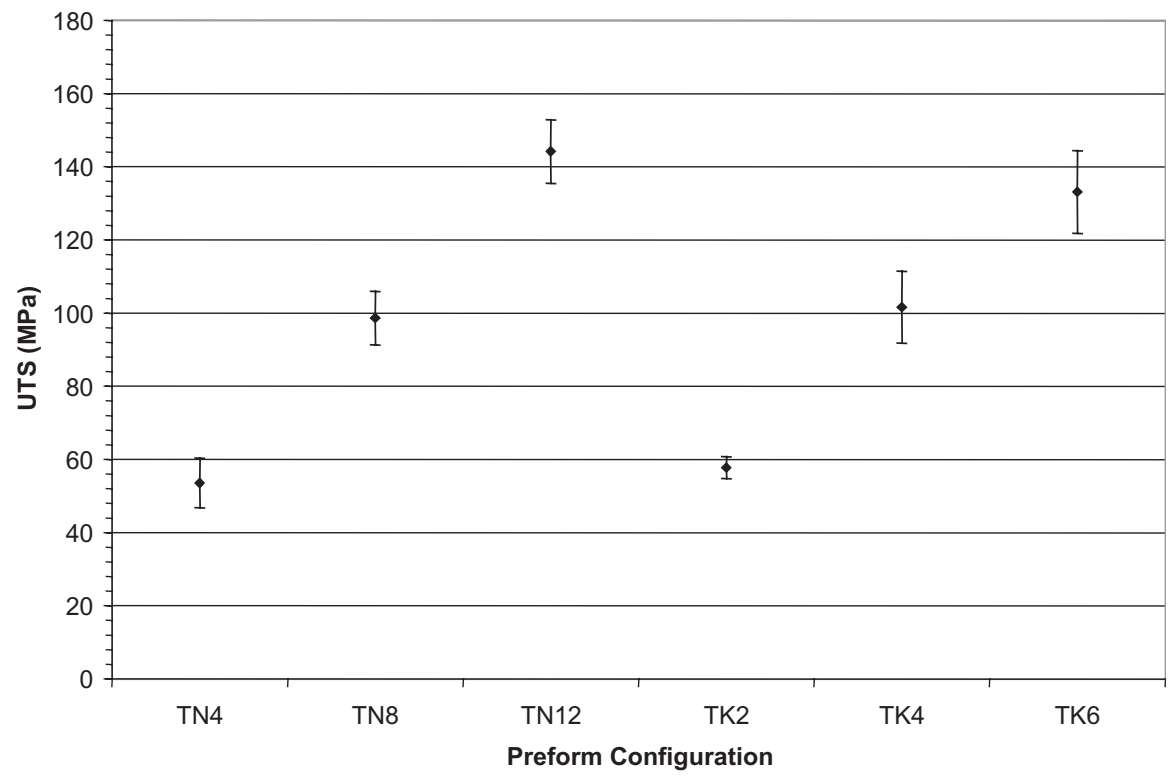

Figure 6. Ultimate tensile strength of specimens for each preform configuration. 
Figure 7 contains data for elastic modulus for the six preform configurations, with error bars drawn again using a 95\% confidence interval. Stiffness results are observed to follow the same trends exhibited by the strength values. The stiffness is found to be similar for thick and thin mats at the same fiber content, and increases linearly with fiber content. Stiffness data, however, exhibits less improvement with increased fiber volume fraction, with approximately $100 \%$ increase in modulus between 6.84 and $24.83 \%$ fiber volume fraction. Stiffness data is also found to have lower statistical variation, with a range between 6.0 and $14.7 \%$ and an average of $9.5 \%$. Stiffness results exhibit even lower variation between thick and thin mats compared with strength results. The linear increase of tensile modulus of resin transfer molded composites up to $50 \%$ fiber volume fraction is also reported by Oksman [2].

Three-point bending test is also performed on molded parts to examine potential variations in mechanical properties introduced by additional interface layers of thin mats. It may be possible that these additional interfaces could weaken interlaminar shear strength of the composite material. Half of the specimens from position 1 are cut into three $38.1 \mathrm{~mm}$ ( $1.5 \mathrm{in}$.) segments, and only the center segment is used for three-point bending test. A total of five tests are performed for each configuration. Measured short-beam shear strength values obtained from this test are presented in Figure 8. Short-beam shear strength is observed to be similar for thick and thin mats, with larger variation $(7 \%)$ between mat types at $24.83 \%$ volume fraction. Although increase in shear strength is linear with volume fraction, thin mats exhibit the largest deviation from linearity of all mechanical test data presented. This slight deviation from linearity may be attributed to higher statistical variations in preform density. In particular, variations in mats are less likely to even out over fewer layers, thus leading to higher uncertainties at lower fiber content.

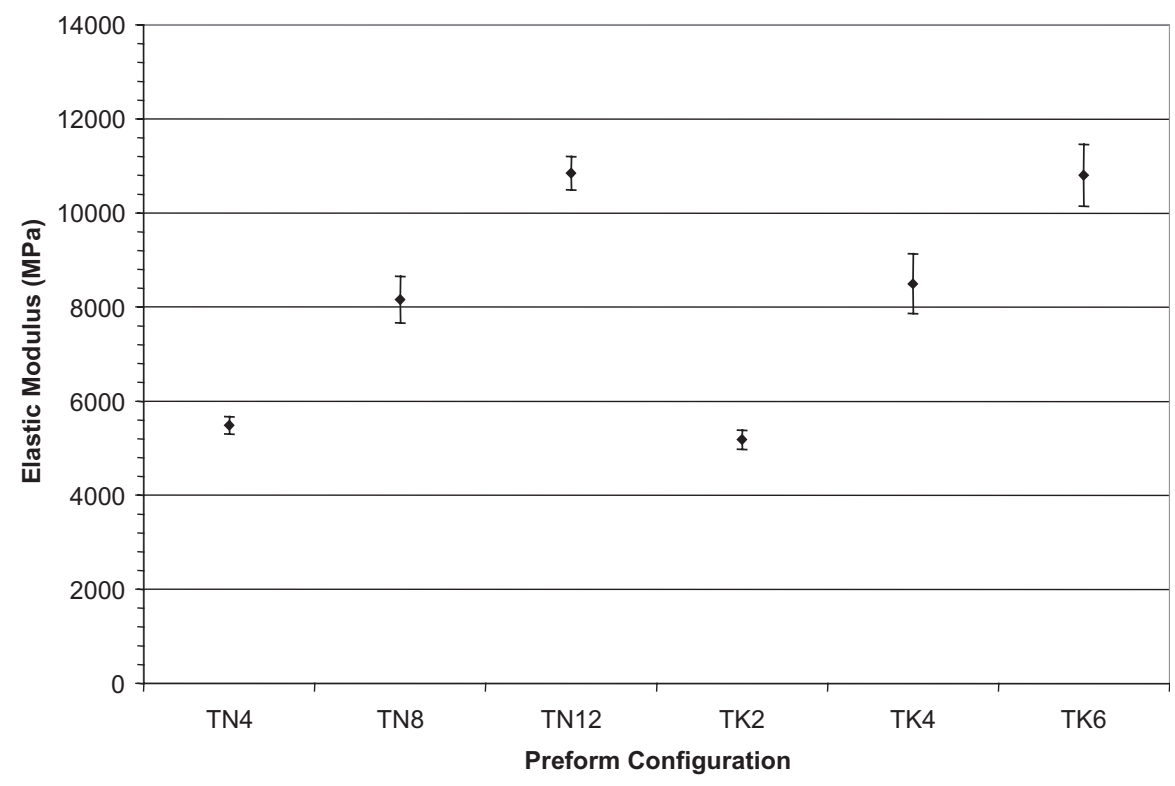

Figure 7. Elastic modulus of specimens for each preform configuration. 


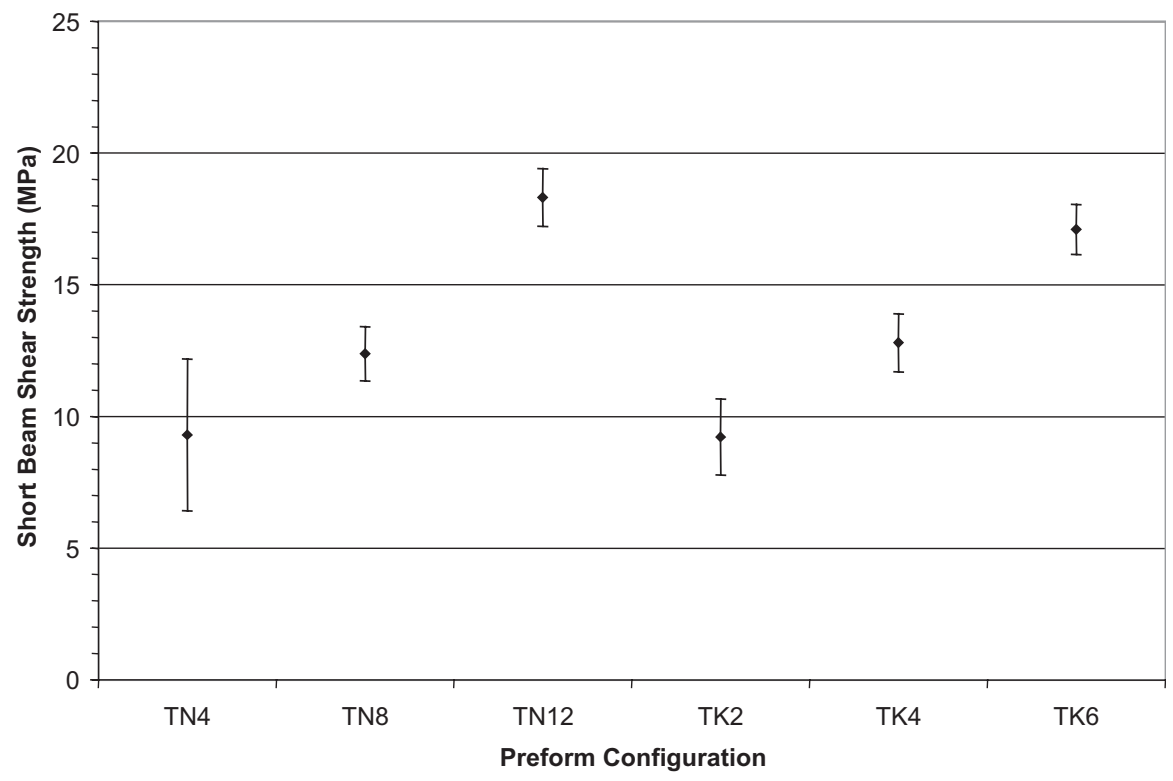

Figure 8. Short beam shear strength of specimens for each preform configuration.

Ultimate tensile strength, elastic modulus, and short-beam shear strength results show that planar preform density does not affect mechanical properties within the range of volume fractions studied. However, the potential for differences in filling patterns between thick and thin mat configurations exists, particularly at low volume fractions where fluid paths between layers may be significantly altered by changing the number of layers used.

\section{Permeability Results}

As described in the previous section on pressure measurement, experiments are performed to determine the transient pressure on the bottom mold wall at $R=12.7 \mathrm{~mm}$ ( 0.5 in.). To quantify the effect of mat type on injection pressure, permeability is obtained from pressure data using Equation (12). The permeability $K_{r r}$ is obtained by minimizing the error in the least squares curve fit between Equation (12) and transient pressure data during filling.

Curve fits to representative injection pressure data from the filling of three disks containing preform configurations TK2, TK4, and TK6 (i.e., 2, 4, and 6 layers of thick mats respectively) are depicted in Figure 9. Solid lines in Figure 9 represent measured values, while dashed lines show curve fits used to obtain permeability. Maximum pressure observed in each filling increases with fiber content, with maximum pressures of approximately 40,110 , and $160 \mathrm{kPa}$ observed for TK2, TK4, and TK6, respectively. A brief startup period is observed in which curve fits do not match measured pressure values due to hose bulging and possibly inlet effects, especially at higher volume fraction. It has been shown that mat deformation at the inlet gate may have considerable effect on fill pressure [41,42], which may also contribute to the observed startup effects. Deviation in pressure from the theoretical values at the startup is minimized by reinforcing the hose leading to mold inlet and reducing the total hose length. Results show that pressure data 


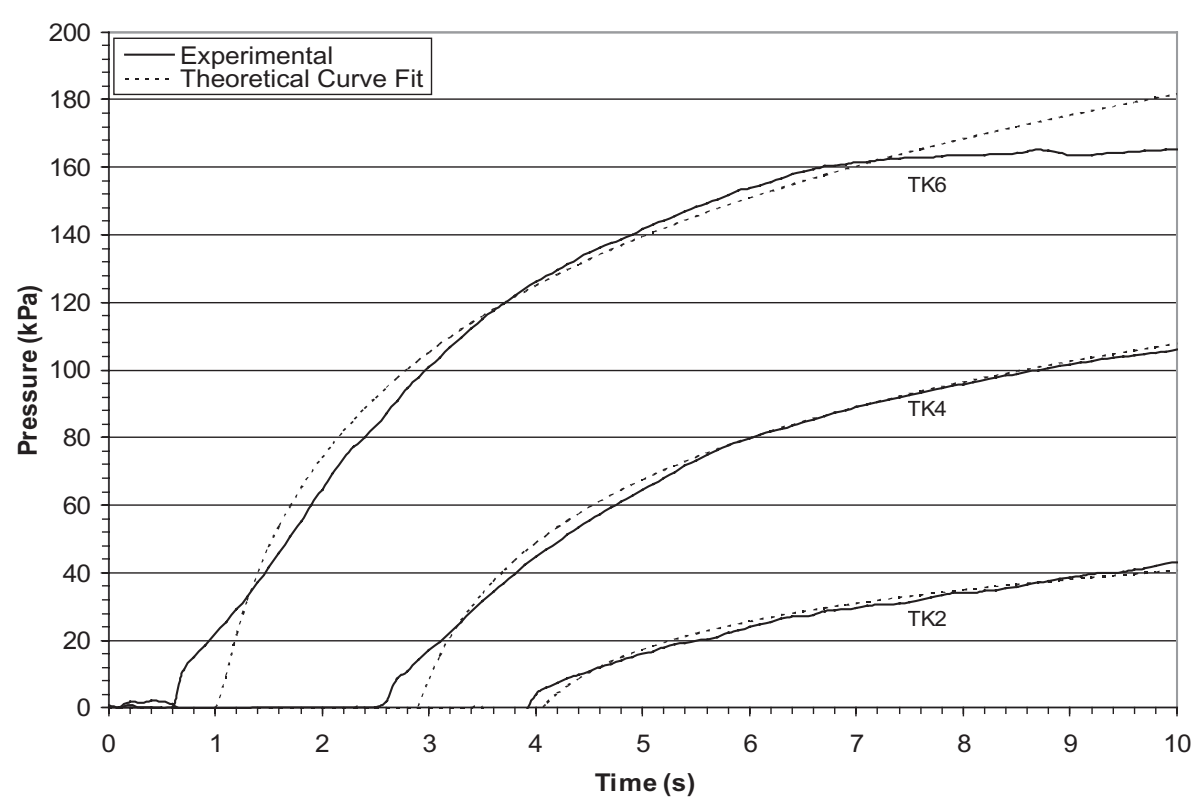

Figure 9. Example pressure curves from disks containing thick mats and theoretical curve fit used to determine permeability. TK2: 2 layers of thick mats (i.e., $v_{f}=6.84 \%$ ); TK4: 4 layers of thick mats (i.e., $\left.v_{f}=15.55 \%\right) ;$ TK6: 6 layers of thick mats (i.e., $v_{f}=24.83 \%$ ).

follows the anticipated trend, and thus curve fits to pressure data are very good after the startup period. At higher volume fractions the mold fills more quickly, thus the pressure is observed to level off after about $6 \mathrm{~s}$ for the TK6 case. Pressure data collected after the mold is filled are not used in the least squares curve fit to calculate the permeability. Best curve fit is obtained for configuration TK2, due to lowest pressures measured for this configuration. Average permeabilities for TK2, TK4, and TK6 are determined as 170.39, 4.89 , and $1.37 \times 10^{-10} \mathrm{~m}^{2}$, respectively.

Representative pressure measurement for thin mat configurations TN4, TN6, and TN12, and their respective curve fits, are shown in Figure 10. Observed molding pressures for thin mat configurations are much lower compared to thick mats at same fiber volume fraction. Theoretical pressure curves generated from curve fits match measured values very well after a short startup period, with TN12 pressure fit ending earlier than the others due to faster fill times at higher fiber content. Measured average permeabilities for TN4, TN6, and TN12 configurations are 556.71, 7.23, and $2.33 \times 10^{-10} \mathrm{~m}^{2}$, respectively. These values are considerably higher than those measured for thick mat configurations, thus indicating lower molding pressure requirements.

Average permeability values for the six preform configurations are shown together in Figure 11, with error bars drawn using 95\% confidence interval. Error bars in permeability values for 15.55 and $24.83 \%$ volume fraction are very small, indicating very repeatable pressure measurements. At least three experiments are performed for each configuration to obtain averaged permeability values. Average permeability values for the six configurations are also given in Table 2 . Permeability ratio in Table 2 is defined as ratio of thin to thick mat permeability at same fiber volume fraction, and represents the expected increase in injection pressure when thick mats are used as opposed to thin mats. Table 2 shows significantly higher permeability values for thin mats at all fiber volume 


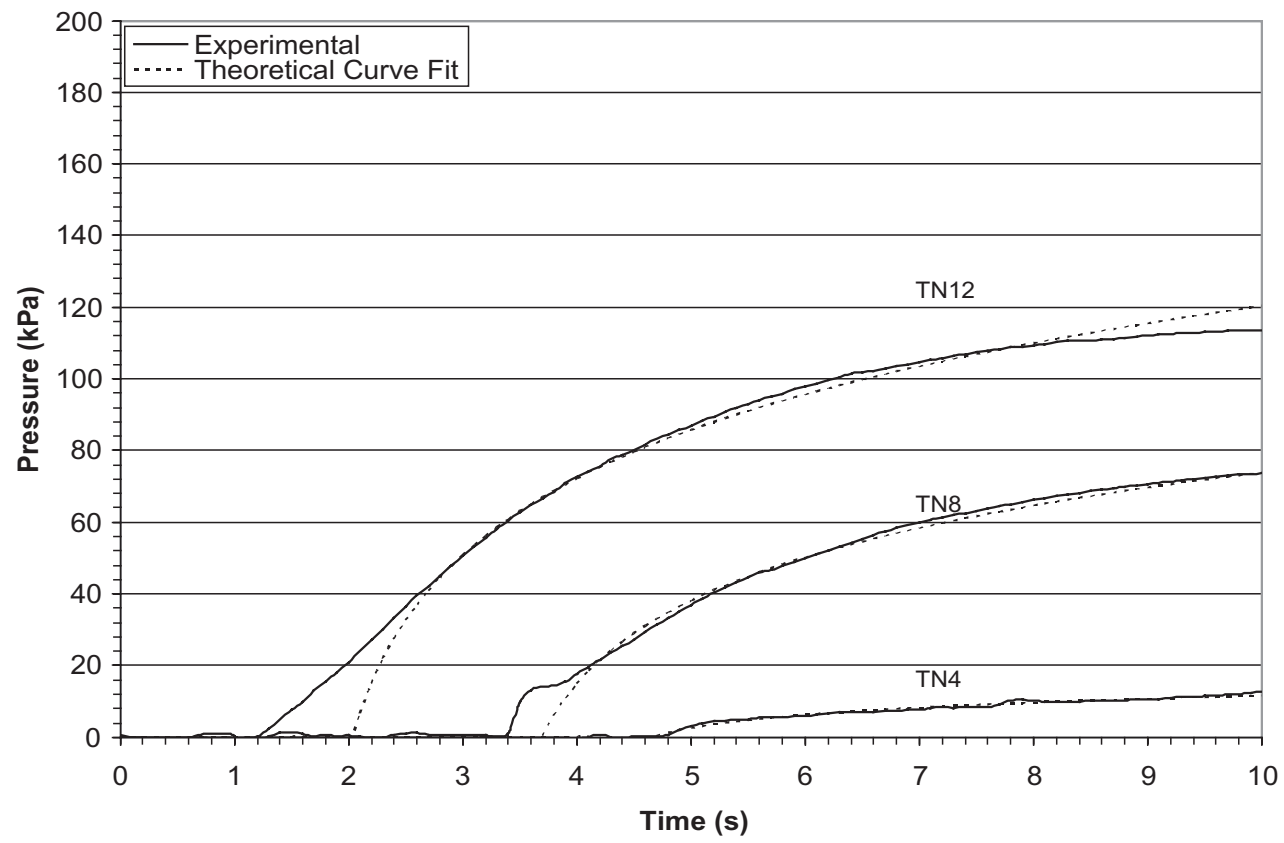

Figure 10. Example pressure curves from disks containing thin mats and theoretical curve fit used to determine permeability. TN4: 4 layers of thin mats (i.e., $v_{f}=6.84 \%$ ); TN8: 8 layers of thin mats (i.e., $\left.v_{f}=15.55 \%\right) ;$ TN12: 12 layers of thin mats (i.e., $v_{f}=24.83 \%$ ).

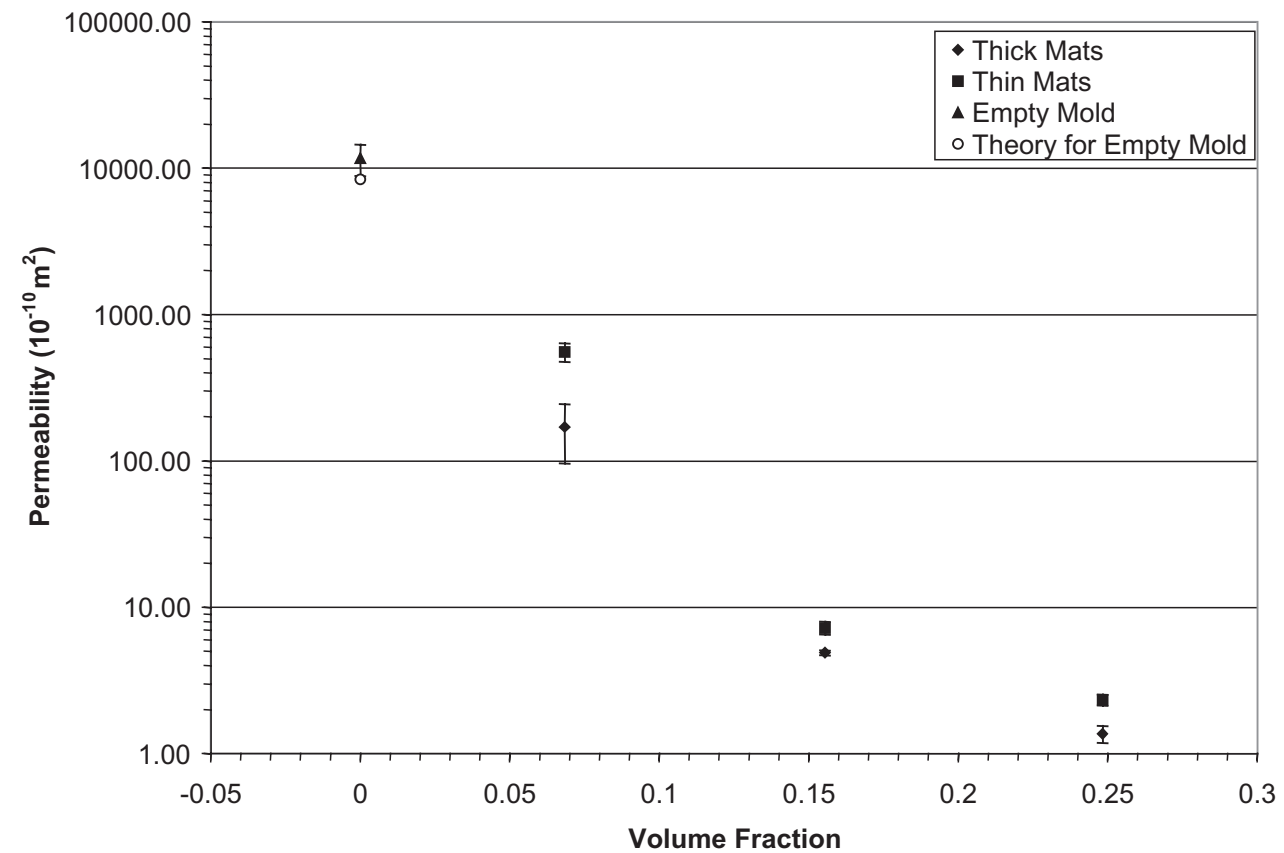

Figure 11. Permeability results obtained for each preform configuration. Theoretical permeability for empty mold is obtained from Equation (14). 
Table 2. Measured permeability for each mat configuration and ratio between permeabilities of thick and thin mats.

\begin{tabular}{lccc}
\hline & $\begin{array}{c}\text { Thick mats } \\
\text { TK2, TK4, TK6 } \\
\text { permeability }\left(\mathbf{1 0 ^ { - 1 0 }} \mathbf{~}^{\mathbf{2}}\right)\end{array}$ & $\begin{array}{c}\text { Thin mats } \\
\text { TN4, TN8, TN12 } \\
\text { permeability }\left(\mathbf{1 0 ^ { - 1 0 }} \mathbf{~}^{\mathbf{2}}\right)\end{array}$ & $\begin{array}{c}\text { Permeability ratio } \\
\text { (TN/TK) }\end{array}$ \\
\hline 6.84 & $170.39 \pm 74.31$ & $556.71 \pm 82.17$ & 3.27 \\
15.55 & $4.89 \pm 0.18$ & $7.23 \pm 0.73$ & 1.48 \\
24.83 & $1.37 \pm 0.18$ & $2.33 \pm 0.20$ & 1.71 \\
\hline
\end{tabular}

fractions. Permeability decreases by two orders of magnitude as volume fraction increases from 6.84 to $24.83 \%$, with largest decrease in permeability observed between 6.84 and $15.55 \%$ fiber content. At $6.84 \%$ fiber volume fraction, permeability ratio is the highest at 3.27 , indicating thick mats have over three times the molding pressure requirements of thin mats. At 15.55 and $24.83 \%$, permeability ratios of 1.47 and 1.71 are obtained. These ratios are lower than the one observed at $6.84 \%$ fiber content, but still represent considerable increase in molding pressure for thick mats.

Measured permeability values are similar in magnitude to those reported for random mats in the literature [43-46]. For example, Wirth and Gauvin, using pressure transducers mounted in a channel-shaped mold, measured permeabilities of 99 and $49 \times 10^{-10} \mathrm{~m}^{2}$ for volume fractions of 11 and $18 \%$, respectively [43]. At 17\% fiber volume fraction, Luce et al. measured a permeability value of $30 \times 10^{-10} \mathrm{~m}^{2}$ using radial flow experiments [44]. Trevino et al. reported permeabilities for random mats between 1.5 and $3.5 \times 10^{-10} \mathrm{~m}^{2}$ for fiber contents between 25 and $45 \%$ [22]. Values presented in the current study are also consistent with results from Kim et al. [45], and Berker and Sun [46].

An effective permeability, calculated from pressure data obtained by injecting corn syrup-water mixture into an empty mold cavity, is also included in Figure 11. For this case, it is possible to calculate a theoretical effective permeability from Darcy's equation. Effective theoretical permeability is obtained by comparing theoretical pressure in an empty disk with pressure obtained from Equation (8) for a porous media. Transient pressure at the transducer for the configuration depicted in Figure 5 is obtained using Navier-Stokes equations. Neglecting inertia terms, pressure at $r=R$ for an empty mold is found to be,

$$
P(t)=\frac{3 Q \mu}{4 \pi H^{3}} \ln \frac{R_{f}(t)}{R} .
$$

Equation (13) is similar in form to Equation (8), which is for transient pressure in a cavity containing preform. For the limiting case of zero fiber content (i.e., $v_{f}=0$ ), Equations (8) and (13) can be compared to obtain an expression for an effective radial permeability in terms of the gap width as,

$$
K_{\text {eff }}=\frac{H^{2}}{3} \text {. }
$$

Theoretical value of effective permeability in Figure 11 is calculated to be $8.4 \times 10^{-7} \mathrm{~m}^{2}$, which is consistent with the average measured value of $11.7 \times 10^{-7} \mathrm{~m}^{2}$. 


\section{CONCLUDING REMARKS}

Results are presented demonstrating effects of fiber volume fraction and planar preform density (i.e., mat thickness) on mechanical properties and injection pressure of resin transfer molded disks. At same fiber content, planar preform density has negligible effect on mechanical properties, demonstrated by comparable values for elastic modulus, tensile strength, and short-beam shear strength. Mechanical properties are observed to increase linearly between 6.84 and $24.83 \%$ fiber volume fraction, with average increase of about $150 \%$ for ultimate tensile strength, and $100 \%$ for elastic modulus and shortbeam shear strength. Despite having negligible effect on mechanical properties, mat thickness is shown to have significant effect on injection pressure. Effect of mat thickness on injection pressure is quantified using differences in permeability values. A pressure-matching technique to measure permeability using the transient pressure data from a single pressure transducer is presented. The measurement technique is simpler and advantageous over other techniques currently used in the literature, that require the use of multiple transducers or tracking of fluid front motion in addition to pressure measurement. Permeabilities measured for thin mats are observed to be $48-227 \%$ higher than those measured for thick mats, thus resulting in significant reduction of injection pressure by $40-70 \%$ for fiber volume fractions ranging from $24.83-6.84 \%$, respectively. Ability to reduce injection pressure or cycle time at same fiber content without degradation in mechanical properties could lead to less expensive molding processes.

\section{REFERENCES}

1. Naik, R.A. (1995). Failure Analysis of Woven and Braided Fabric Reinforced Composites, Journal of Composite Materials, 29(17): 2334-2363.

2. Oksman, K. (2001). High Quality Flax Fiber Composites Manufactured by the Resin Transfer Moulding Process, Journal of Reinforced Plastics and Composites, 20(7): 621-627.

3. Pearce, N.R.L, Summerscales, J. and Guild, F.J. (2000). Improving the Resin Transfer Moulding Process for Fabric-Reinforced Composites by Modification of the Fabric Architecture, Composites Part A, 31(12): 1433-1441.

4. Wang, Y. (1999). Effect of Consolidation Method on the Mechanical Properties of Nonwoven Fabric Reinforced Composites, Applied Composite Materials, 6(1): 19-34.

5. Wang, Y. and Li, J. (1995). Properties of Composites Reinforced with E-Glass Nonwoven Fabric, Journal of Advanced Materials, 26(3): 28-34.

6. Goodwin, A.A., Howe, C.A. and Paton, R.J. (1997). The Role of Voids in Reducing the Interlaminar Shear Strength in RTM Laminates, In: Scott, M.L. (ed.), Proceedings of ICCM-11, Vol. 4, pp. 11-19.

7. Lee, C.-L. and Wei, K.-H. (2000). Effect of Material and Process Variables on the Performance of Resin-Transfer-Molded Epoxy Fabric Composites, Journal of Applied Polymer Science, 77(10): 2149-2155.

8. Patel, N., Rohatgi, V. and Lee, L.J. (1993). Influence of Processing and Material Variables in Resin-Fiber Interface in Liquid Composite Molding, Polymer Composites, 14(2): 161-172.

9. Lee, C.-L. and Wei, K.-H. (2000). Resin Transfer Molding (RTM) Process of High Performance Epoxy Resin. II: Effect of Process Variables on the Physical, Static and Dynamic Mechanical Behavior, Polymer Engineering and Science, 40(4): 935-943.

10. Bickerton, S., Sozer, E.M., Graham, P.J. and Advani, S.G. (2000). Fabric Structure and Mold Curvature Effects on Preform Permeability and Mold Filling in the RTM Process. Part I. Experiments, Composites Part A, 31(5): 423-438. 
11. Bickerton, S., Sozer, E.M., Simacek, P. and Advani, S.G. (2000). Fabric Structure and Mold Curvature Effects on Preform Permeability and Mold Filling in the RTM Process. Part II. Predictions and Comparisons with Experiments, Composites Part A, 31(5): 439-458.

12. Mogavero, J. and Advani, S.G. (1997). Experimental Investigation of Flow Through MultiLayered Preforms, Polymer Composites, 18(5): 649-655.

13. Pearce, N.R.L., Guild, F.J. and Summerscales, J. (1998). An Investigation into the Effects of Fabric Architecture on the Processing and Properties of Fiber Reinforced Composites Produced by Resin Transfer Moulding, Composites Part A, 29(1): 19-27.

14. Adams, K.L. and Rebenfeld, L. (1987). In-Plane Flow of Fluids in Fabrics: Structure/Flow Characterization, Textile Research Journal, 57(11): 647-654.

15. Darcy, H.P.G. (1856). Les Fontaines Public de la Ville de Dijon, Delmont, 306, Paris.

16. Carman, P.C. (1937). Fluid Flow Through a Granular Bed, Transaction of the Institution of Chemical Engineers, 15: 150-166.

17. Gutowski, T.G., Morigaki, T. and Cai, Z. (1987). The Consolidation of Laminate Composites, Journal of Composite Materials, 21(2): 172-188.

18. Gebart, B.R. (1992). Permeability of Unidirectional Reinforcements for RTM, Journal of Composite Materials, 26(8): 1100-1133.

19. Bruschke, M.V. and Advani, S.G. (1990). A Finite Element/Control Volume Approach to Mold Filling in Anisotropic Porous Media, Polymer Composites, 11(6): 398-405.

20. Ngo, N.D. and Tamma, K.K. (2001). Microscale Permeability Predictions of Porous Fibrous Media, International Journal of Heat and Mass Transfer, 44(16): 3135-3145.

21. Williams, J.G., Morris, C.E.M. and Ennis, B.C. (1974). Liquid Flow Through Aligned Fiber Beds, Polymer Engineering and Science, 14(6): 413-419.

22. Trevino, L., Rupel, K., Young, W.B., Liou, M.J. and Lee, L.J. (1991). Analysis of Resin Injection Molding in Molds with Preplaced Fiber Mats. I: Permeability and Compressibility Measurements, Polymer Composites, 12(1): 20-29.

23. Young, W.B., Rupel, K., Lee, L.J. and Liou, M.J. (1991). Analysis of Resin Injection Molding in Molds with Preplaced Fiber Mats. II: Numerical Simulation and Experiments of Mold Filling, Polymer Composites, 12(1): 30-38.

24. Calhoun, D.R., Yalvaç, S., Wetters, D.G. and Raeck, C.A. (1996). Critical Issues in Model Verification for the Resin Transfer Molding Process, Polymer Composites, 17(1): 11-22.

25. Adams, K.L., Miller, B. and Rebenfeld, L. (1986). Forced In-Plane Flow of an Epoxy Resin in Fibrous Network, Polymer Engineering and Science, 26(20): 1434-1441.

26. Adams, K.L. and Rebenfeld, L. (1991). Permeability Characteristics of Multilayer Fiber Reinforcements. Part I: Experimental Observations, Polymer Composites, 12(3): 179-185.

27. Adams, K.L. and Rebenfeld, L. (1991). Permeability Characteristics of Multilayer Fiber Reinforcements. Part II: Theoretical Model, Polymer Composites, 12(3): 186-190.

28. Gauvin, R., Trochu, F., Lemenn, Y. and Diallo, L. (1996). Permeability Measurement and Flow Simulation Through Fiber Reinforcement, Polymer Composites, 17(1): 34-42.

29. Sheard, J., Senft, V., Mantell, S.C. and Vogel, J.H. (1998). Determination of Corner and Edge Permeability in Resin Transfer Molding, Polymer Composites, 19(1): 96-105.

30. Ferland, P., Guittard, D. and Torchu, F. (1996). Concurrent Methods for Permeability Measurement in Resin Transfer Molding, Polymer Composites, 17(1): 149-158.

31. Dungan, F.D., Senoguz, M.T., Sastry, A.M. and Faillaci, D.A. (2001). Simulation and Experiments on Low Pressure Permeation of Fabrics: Part I-3D Modeling of Unbalanced Fabric, Journal of Composite Materials, 35(14): 1250-1284.

32. Mahale, A.D., Prud'Homme, R.K. and Rebenfeld, L. (1992). Quantitative Measurement of Voids Formed During Liquid Impregnation of Nonwoven Multifilament Glass Networks Using an Optical Visualization Technique, Polymer Engineering and Science, 32(5): 319-326.

33. Patel, N. and Lee, L.J. (1996). Modeling of Void Formation and Removal in Liquid Composite Molding. Part II: Model Development and Implementation, Polymer Composites, 17(1): 104-114.

34. Dhillon, I.S. (2000). Resin Transfer Molding of Fiber Reinforced Composite Disks, Masters Thesis, University of Oklahoma, Norman, OK. 
35. ASTM D3039/D3039M-95a. 1997.

36. ASTM D2344/D2344M-00. 2000.

37. Parnas, R.S., Flynn, K.M. and Dal-Favero, M.E. (1997). A Permeability Database for Composites Manufacturing, Polymer Composites, 18(5): 623-633.

38. Lai, Y-H., Khomami, B. and Kardos, J.L. (1997). Accurate Permeability Characterization of Preforms Used in Polymer Matrix Composite Fabrication Processes, Polymer Composites, 18(3): 368-377.

39. Olivero, K.A. (2000). Gravity Effects on Fluid Front Dynamics During Mold Filling, Masters Thesis, University of Oklahoma, Norman, OK.

40. Olivero, K.A., Barraza, H.J., O'Rear, E.A. and Altan, M.C. (2002). Effect of Injection Rate and Post-fill Cure Pressure on Properties of Resin Transfer Molded Disks, Journal of Composite Materials, 36(16): 2011-2028.

41. Han, K., Trevino, L., Lee, L.J. and Liou, M. (1993). Fiber Mat Deformation in Liquid Composite Molding. I: Experimental Analysis, Polymer Composites, 14(2): 144-150.

42. Han, K., Trevino, L., Lee, L.J. and Liou, M. (1993). Fiber Mat Deformation in Liquid Composite Molding. II: Modeling, Polymer Composites, 14(2): 151-160.

43. Wirth, S. and Gauvin, R. (1998). Experimental Analysis of Mold Filling in Compression Resin Tranfer Molding, Journal of Reinforced Plastics and Composites, 17(16): 1414-1430.

44. Luce, T.L., Advani, S.G., Howard, J.G. and Parnas, R.S. (1995). Permeability Characterization. Part 2: Flow Behavior in Multiple-Layer Preforms, Polymer Composites, 16(6): 446-458.

45. Kim, B.Y., Nam, G.J. and Lee, J.W. (2002). Optimization of Filling Processes in RTM Using a Genetic Algorithm and Experimental Design Method, Polymer Composites, 23(1): 72-86.

46. Berker, B. and Sun, J.Q. (1998). Permeability Estimation in Resin Transfer Molding, Journal of Materials Processing \& Manufacturing Science, 6(3): 205-211. 